\title{
KARAKTERISTIK PASIEN DIABETES MELLITUS TIPE 2 YANG MENDAPATKAN TERAPI ANTIDIABETIK ORAL DI RSUD DR. H. MOCH.ANSARI SALEH BANJARMASIN \\ (Evaluation Of Type 2 Diabetes Mellitus Patient's Compliance That Gets Antidiabetic Oral Therapy In Dr. H. Moch.Ansari Saleh Banjarmasin)
}

\author{
Muliyani, Nazhipah Isnani \\ Program Studi D-III Farmasi, \\ Politeknik Unggulan Kalimantan \\ Email:muliyaniaya@gmail.com
}

\begin{abstract}
Diabetes mellitus (DM) is a collection of metabolic symptoms that arise in a person caused by an increase in blood glucose due to damage to insulin secretion or resistance to insulin or both. In Indonesia, the number of persons with diabetes mellitus, the more the year also shows a very high increase. In 2000, the number of people with DM in Indonesia was 8.4 million and is estimated to reach 21.3 million by 2030 . This study aims to determine the characteristics of patients, the level of patient compliance. The research method is a Crossectional Observational study by taking patient data prospectively by tracing the previous documents, namely on the medical record sheets of inpatients for the period June - July 2017. The results of this study indicate that based on the characteristics of the research subjects as many as 28 respondents. Age $<55$ years as many as 12 people (42.9\%) and $>55$ years as many as 16 people $(57.1 \%)$, the least level of education is $>$ SMA as many as 11 people (39.3\%) and <SMA as many as 17 people $(60.7 \%), 16$ people were female (57.1\%) and as many as 12 people (42.9\%), 23 people worked $(82.1 \%)$, and those who did not work were 5 people (17, 9\%), the duration of patients suffering from type 2 diabetes mellitus was mostly $>5$ years as many as 18 respondents $(64.3 \%)$ and at least $<5$ years as many as $10(35.7 \%)$, types of Monotherapy treatment as many as 16 respondents $(57.43 \%)$ and a combination of 12 $(42.57 \%)$.
\end{abstract}

Keywords : Type 2 diabetes mellitus, patient compliance, oral antidiabetic

\section{ABSTRAK}

Diabetes melitus (DM) merupakan kumpulan gejala metabolik yang timbul pada diri seseorang yang disebabkan oleh adanya peningkatan glukosa darah akibat rusaknya sekresi insulin atau resistensi terhadap insulin atau keduanya. Di Indonesia, jumlah penyandang DM semakin tahun juga semakin menunjukkan peningkatan yang sangat tinggi. Pada tahun 2000, jumlah penderita DM di Indonesia sebanyak 8,4 juta jiwa dan diperkirakan akan mencapai angka 21,3 juta jiwa pada tahun 2030 nanti. Penelitian ini bertujuan untuk mengetahui karakteristik pasien, tingkat kepatuhan pasien. Metode penelitian merupakan penelitian Observasional Crossectional dengan mengambil data pasien secara prospektif dengan melakukan penelusuran dokumen terdahulu, yaitu pada lembar rekam medik pasien rawat inap periode Juni - Juli 2017. Hasil penelitian ini menunjukkan bahwa Berdasarkan karakteristik subjek penelitian sebanyak 28 responden. Usia $<55$ tahun sebanyak 12 orang $(42,9 \%)$ dan $>55$ tahun sebanyak 16 orang $(57,1 \%)$, tingkat pendidikan yang paling sedikit adalah > SMA sebanyak 11 orang (39,3\%) dan <SMA sebanyak 17 orang $(60,7 \%)$, 16 orang berjenis kelamin perempuan $(57,1 \%)$ dan sebanyak 12 orang $(42,9 \%), 23$ orang yang bekerja $(82,1 \%)$, dan yang tidak bekerja sebanyak 5 orang $(17,9 \%)$, lama pasien menderita DM tipe 2 sebagian besar $>5$ tahun sebanyak 18 responden $(64,3 \%)$ dan paling sedikit $<5$ tahun sebanyak 10 (35,7\%), jenis pengobatan Monoterapi sebanyak 16 responden $(57,43 \%)$ dan Kombinasi sebanyak $12(42,57 \%)$. 


\section{Kata kunci : Diabetes mellitus tipe 2, kepatuhan pasien, antidiabetik oral}

\section{PENDAHULUAN}

Diabetes melitus (DM) merupakan kumpulan gejala metabolik yang timbul pada diri seseorang yang disebabkan oleh adanya peningkatan glukosa darah akibat rusaknya sekresi insulin atau resistensi terhadap insulin atau keduanya (Scarano et al., 2006). DM telah dikategorikan sebagai penyakit global oleh World Health Organization (WHO) dengan jumlah penderita di dunia mencapai 199 juta jiwa pada tahun 2009. Menurut statistik dari studi Global Burden of Disease WHO tahun 2004, Indonesia menempati peringkat pertama di Asia Tenggara, dengan prevalensi penderita sebanyak 8,426,000 jiwa di tahun 2000 dan diproyeksi meningkat 2,5 kali lipat sebanyak $21,257,000$ penderita pada tahun 2030 (WHO, 2009).

Secara epidemiologi, diperkirakan bahwa pada tahun 2030 prevalensi Diabetes Melitus (DM) di Indonesia mencapai 21,3 juta orang (Diabetes Care, 2004). Sedangkan hasil Riset kesehatan Dasar (Riskesdas) tahun 2007, diperoleh bahwa proporsi penyebab kematian akibat DM pada kelompok usia 45-54 tahun di daerah perkotaan menduduki ranking ke-2 yaitu 14,7\% dan daerah pedesaan, DM menduduki ranking ke-6 yaitu 5,8\%. Diabetes melitus (DM) saat ini merupakan penyakit yang banyak dijumpai dengan prevalensi $4 \%$ diseluruh dunia. Diperkirakan pada tahun 2025, prevalensinya penyakit ini akan meningkat mencapai 5,4\%. Meskipun belum didapat data yang resmi diperkirakan prevalensinya akan terus meningkat.

Berbagai penelitian menunjukkan bahwa kepatuhan pasien pada pengobatan penyakit yang bersifat kronis pada umumnya rendah. Penelitian yang melibatkan pasien berobat jalan menunjukkan bahwa lebih dari $70 \%$ pasien tidak minum obat sesuai dengan dosis yang seharusnya (Basuki, 2009). Menurut laporan WHO pada tahun 2003, kepatuhan rata-rata pasien pada terapi jangka panjang terhadap penyakit kronis di negara maju hanya sebesar $50 \%$, sedangkan di negara berkembang, jumlah tersebut bahkan lebih rendah (Asti, 2006).

Tingkat kepatuhan penderita dalam minum obat merupakan salah satu faktor yang menentukan keberhasilan pengobatan, terutama dalam hal ini pada penyakit kronis. Kepatuhanminum obat didefinisikan sebagai sejauh mana perilaku pasien taat dengan nasihat medis, sejauh mana perilaku pasien sehubungan dengan minum obat, sesuai dengan rekomendasi yang diberikan oleh tenaga kesehatan atau tidak. Dapat terlihat pada penderita yang mengkonsumsi obat atau tidak, sesuai dosis, frekuensi penggunaan serta cara penggunaannya. Kurang kepatuhan merupakan penyebab paling sering untuk kegagalan terapi oral antidiabetes (Mycek, 2001).

Kepatuhan terhadap pengobatan akan mempengaruhi kualitas hidup penderita diabetes (Marra, 2004). Disinilah peran farmasi untuk memberikan informasi yang tepat mengenai segala sesuatu yang berhubungan dengan kondisi dan pengolalaan diabetes. Dengan adanya pemahaman pasien mengenai diabetes diharapkan dapat meningkatkan kepatuhan penderita diabetes.

Memperhatikan hal tersebut di atas, maka perlu dilakukan evaluasi terhadap kepatuhan diabetes melitus tipe 2 di rawat jalan di RSUD Dr. H. Moch. Ansari Saleh Banjarmasin. yang diterapi dengan antidiabetik oral berdasarkan jenis dan jumlah obat. Sehingga dengan melakukan evaluasi terhadap faktor-faktor yang mempengaruhi kepatuhan, pasien diabetes melitus.

\section{METODE PENELITIAN}

Penelitian ini menggunakan metode observational crosssectional dengan mengambil data pasien secara prospektif.

\section{POPULASI DAN SAMPEL PENELITIAN}

Populasi target penelitian adalah pasien diabetes melitus yang berobat di Poliklinik Penyakit Dalam RSUD Dr. H. Moch. Ansari Saleh Banjarmasin. Populasi terjangkau adalah pasien diabetes melitus yang berobat di Poliklinik Penyakit Dalam RSUD Dr. H. Moch. Ansari Saleh Banjarmasin periode April 2016 - Mei 2017. 


\section{KRITERIA INKLUSI DAN EKSKLUSI \\ 1. Kriteria Inklusi}

a. Pasien dewasa berusia antara 18-65 tahun.

b. Pasien dengan diabetes melitus (ICD 10. E 11) yang berobat di Poliklinik Penyakit Dalam RSUD Dr. H. Moch. Ansari Saleh Banjarmasin selama kurun waktu penelitian.

c. Mendapat obat antidiabetik oral

d. Bersedia mengikuti penelitian dengan menandatangani informed consent

e. Pasien menderita diabetes melitus minimal bulan.

\section{Kriteria Eksklusi}
a. Tuli
b. Hamil
c. Buta huruf

\section{HASIL DAN PEMBAHASAN}

Hasil penelitian yang telah dilakukan penelitian adalah sebanyak 28 pasien DM tipe 2 yang memenuhi kriteria inklusi selama periode Juni - Juli 2017, pengambilan data dilaksanakan di rawat jalan poli penyakit dalam Rumah Sakit Ansari Saleh Banjarmasin. Subjek penelitian terdiri dari 16 orang perempuan dan 12 orang laki-laki. Karakteristik responden dalam penelitian ini terdiri dari karakteristik umur, jenis kelamin, pendidikan, pekerjaan, lama pengobatan dan jenis pengobatan. Berikut karakteristik responden dalam penelitian ini:

1. Usia

Distribusi frekuensi usia responden disajikan pada tabel I berikut:

Tabel I . Usia Responden

\begin{tabular}{cccc}
\hline & Karakteristik Pasien & Jumlah & Persentase \\
& & $\mathrm{N}(28)$ & \\
\hline \multirow{2}{*}{ Usia } & $<55$ tahun & 12 & 42,9 \\
& $>55$ tahun & 16 & 57,1 \\
\hline
\end{tabular}

Sumber : data diolah 2017

Berdasarkan tabel 1. diketahui bahwa dari 28 responden, dengan usia $<55$ tahun sebanyak 12 orang $(42,9 \%)$ dan $>55$ tahun sebanyak 16 orang $(57,1 \%)$. Hal ini menunjuukan pada usia lanjut pasien DM tipe lebih 2 lebih banyak dibandingkan pada usia sebelum geriatri, hal ini serupa dengan serupa dengan penelitian-penelitian yang pernah dipublikasikan yaitu, (Adikusuma dkk, 2014, Wabe et al, 2011, Jamous et al, 2011, Shams \& Barakat et al,2010) menunjukkan bahwa pada penelitian-penelitian ini rata-rata usia pasien DM tpe 2 pada saat usia lanjut berkisar $50-55$ tahun. Menurut Cantrill dan Wood (2003) insidensi DM tipe 2 meningkat dengan bertambahnya usia karena banyak factor yang mempengaruhi. Penuaan mempengaruhi banyak hormon yang mengatur metabolisme tubuh serta menurunnya fungsi-fungsi organ tubuh. Terutama pada fungsi sel beta pankreas terhadap glukosa yang sensitivitasnya sudah menurun. Penuaan juga mengakibatkan resistensi insulin terkait karena adanya kerusakan post reseptor (Triplit., et al, 20015).

\section{Pendidikan}

Distribusi frekuensi pendidikan responden disajikan pada tabel II berikut:

Tabel II. Pendidikan Responden

\begin{tabular}{lccc}
\hline & Karakteristik Pasien & Jumlah & Persentase \\
& & $N(28)$ & \\
\hline Usia & S SMA & 17 & 60,7 \\
& $\geq$ SMA & 11 & 39,3 \\
\hline & & Sumber: Data diolah, 2017 \\
\hline
\end{tabular}


Berdasarkan tabel II diketahui bahwa dari 28 responden, Subjek dalam penelitian ini dibagi menjadi 2 kategori yaitu tingkat pendidikan yang paling sedikit adalah > SMA sebanyak 11 orang $(39,3 \%)$ dan yang banyak adalah $<$ SMA sebanyak 17 orang $(60,7 \%)$. Dalam penelitian ini yang paling banyak adalah masyarakat dengan pendidikan rendah.

\section{Jenis Kelamin}

Distribusi jenis kelamin responden dalam penelitian ini disajikan pada tabel VIII berikut:

Tabel VIII. Jenis Kelamin Responden

\begin{tabular}{llcc}
\hline \multicolumn{2}{c}{ Karakteristik Pasien } & Jumlah & Persentase \\
\hline Jenis & Laki-laki & N (28) & 42,9 \\
\cline { 2 - 5 } Kelamin & Perempuan & 12 & 57,1 \\
\hline
\end{tabular}

Sumber: Data diolah, 2017

Berdasarkan tabel VIII diketahui bahwa dari 28 responden sebagian besar berjenis kelamin perempuan, yaitu sebanyak 16 orang perempuan $(57,1 \%)$ dan sebanyak 12 orang laki-laki $(42,9 \%)$, berjenis kelamin laki-laki. Pada penelitian ini angka kejadian pada perempuan lebih tinggi dibandingkan pada laki-laki, hal ini sama dengan penelitian sebelumnya yang serupa (Triplit et al, 2005) menunjukkan di Amerika Serikat, insidensi DM tipe 2 lebih umum terjadi pada perempuan daripada laki-laki dan (Adikusuma dkk, 2014) pada penelitiannya yang dilakukan di salah satu Rumah Sakit di Yogyakarta menunjukkan pasien DM tipe 2 pada perempuan lebih banyak terjadi dari pada pada laki-laki, dari hasil penelitian menunjukkan dari 56 orang pasien, 35 orang terjadi pada perempuan dann 21 orang terjadi pada laki-laki. Hal ini tidak mutlak terjadi karena banyak penelitian yang serupa namun hasilnya bervariasi. Sehingga tidak menunjukkan perbedaan yang signifikan antara perempuan maupun laki-laki menurut American Diabetes Association menyatakan bahwa jenis kelamin bukanlah faktor resiko terjadinya diabetes mellitus melainkan faktor seperti obesitas, hipertensi, dislipidemia, riwayat diabetes gestasional, serta riwayat melahirkan bayi > 4 kg (Adikusuma dkk, 2014).

\section{Pekerjaan}

Distribusi status pekerjaan responden dalam penelitian ini disajikan pada tabel IX berikut:

Tabel IX. Distribusi Pekerjaan Responden

\begin{tabular}{lccc}
\hline & Karakteristik Pasien & Jumlah & Persentase \\
& & $\mathrm{N}(28)$ & \\
\hline Status & Bekerja & 5 & 17,9 \\
Pekerjaan & Tidak Bekerja & 23 & 82,1 \\
\hline
\end{tabular}

Sumber: Data diolah, 2017

Berdasarkan tabel IX diketahui bahwa dari 28 responden sebagian besar tidak bekerja, yaitu sebanyak 23 orang (82,1\%), dan yang tidak bekerja sebanyak 5 orang (17,9\%). Dalam penelitian ini yang mendominasi adalah pasien yang tidak bekerja, dalam kategori ini yang dimaksud adalah ibu rumah tangga.

\section{Lama Menderita Diabetes Mellitus Tipe 2}

Distribusi lama menderita DM tipe 2 responden dalam penelitian ini disajikan pada tabel $X$ berikut:

Tabel Distribusi lama pengobatan

\begin{tabular}{lccc}
\hline \multicolumn{2}{c}{ Karakteristik Pasien } & Jumlah & Persentase \\
& & $\mathrm{N}(28)$ & \\
\hline Lama DM tipe 2 & $<5$ tahun & 10 & 35,7 \\
& $\geq 5$ tahun & 18 & 64,3 \\
\hline
\end{tabular}

Sumber: Data diolah, 2017 
Berdasarkan tabel diketahui bahwa dari 28 responden, lama pengobatan sebagian besar $>5$ tahun sebanyak 18 responden $(64,3 \%)$ dan paling sedikit $<5$ tahun sebanyak $10(35,7 \%)$. Durasi penyakit DM tipe 2 menun menunjukkan berapa lama berapa lama pasien tersebut menderita DM tipe 2 sejak ditegakkan diagnosis bahwa pasien tersebut DM tipe 2. Faktor keparahan bahkan pencetus terjadinya komplikasi adalah lama nya menderita DM tipe 2 (Zimmet, 2009). Pada pasien diabetes yang melakukan pengobatan pada umumnya rutin dilakukan setelah lama terdiagnosa Diabetes Mellitus tipe 2 dan timbul dampak-dampak yang tidak diinginkan (Anonim, 2006).

\section{Jenis Pengobatan}

Distribusi jenis pengobatan responden dalam penelitian ini disajikan pada tabel XI berikut:

Tabel XI. Distribusi lama pengobatan

\begin{tabular}{lccc}
\hline \multicolumn{2}{c}{ Karakteristik Pasien } & Jumlah & Persentase \\
& Monoterapi & N (28) & \\
\hline \multirow{2}{*}{ Jenis Pengobatan } & Kombinasi & 16 & 57,43 \\
& Komina & 12 & 42,57 \\
\hline
\end{tabular}

Sumber: Data diolah, 2017

Berdasarkan tabel diketahui bahwa dari 28 responden, jenis pengobatan yang diberikan sebagian besar jenis pengobatan Monoterapi sebanyak 16 responden (57,43\%) dan Kombinasi sebanyak $12(42,57 \%)$.

\section{KESIMPULAN}

Berdasarkan karakteristik responden dalam penelitian ini terdiri dari karakteristik umur usia $<55$ tahun sebanyak 12 orang (42,9\%) dan $>55$ tahun sebanyak 16 orang $(57,1 \%)$, karakteristik jenis kelamin sebanyak 16 orang perempuan $(57,1 \%)$ dan sebanyak 12 orang laki-laki $(42,9 \%)$, karakteristik pendidikan > SMA sebanyak 11 orang $(39,3 \%)$ dan yang banyak adalah <SMA sebanyak 17 orang $(60,7 \%)$. dan jenis pengobatan sebagian besar $>5$ tahun sebanyak 18 responden $(64,3 \%)$ dan paling sedikit $<5$ tahun sebanyak $10(35,7 \%)$. jenis pengobatan Monoterapi sebanyak 16 responden (57,43\%) dan Kombinasi sebanyak 12 (42,57\%).

\section{DAFTAR PUSTAKA}

Adikusuma Irawan, 2014. Evaluasi Tingkat Kepatuhan dan Kualitas Hidup Pasien Diabetes Tipe 2 Yang Mendapatkan Monoterapi dan Kombinasi Terapi Antidiabetik Oral di Rumah Sakit Umum PKU Muhammadiyah Bantul, Yogyakarta.

Anonim, 2006, Pharmaceutical Care untuk Penyakit Diabetes Mellitus, Direktorat Bina Farmasi Klinik dan Komunitas Departemen Kesehatan Republik Indonesia, Jakarta.

Asti, T. 2006. Kepatuhan Pasien : Faktor Penting dalam Keberhasilan Terapi. Info POM, Vol. 7, No. $5, \quad$ diakses Januari 2011 dari http://perpustakaan.pom.go.id/KoleksiLainnya/Buletin\%20Info\%20POM/0506.pdf

Basuki, Endang. 2009. Konseling Medik: Kunci Menuju Kepatuhan Pasien. Majalah Kedokteran Indonesia. Vol.59 No. 2 Februari 2009.

Cantrill, J.A., Wood, J., Diabetes Mellitus, in walker, R., 2003. Clinical pharmacy and therapeutics, $3^{\text {rd }}$ edition, Churcill Livingstone, UK.

Diabetes Care, 2004, Report of the expert committee on the diagnosis and classification of diabetes mellitus ; 26 Suppl 1: S5-20.

Jamous, R.M., Seileh, W.M. Abu Taha, A.S., 2011. Adherence stafication with oral hypoglycemic medication: a pilot study in

Palestine, Int J Clin Pharm; DOI10.1007/s11096-011-9561-7 
Marra G, 2004, The DIAB \& TE.S Project Study Group, The DIAB \& TE.S Project: how patients perceive diabetes and diabetes therapy. Acta Biomed; 75: 164-170.

Scarano, W.R., Messias, A.G., Oliva, S.U., Klinefelter, GR, \& Kempinas, W.G, 2006, Sexual behaviour, sperm quantity and quality after short-therm streptozotocin-induced hyperglycaemia in rats. International Journal Andrology, 29, 482-488.

Triplitt, C.L., Reasner, C.A., and Isley, W.L., 2005.Diabetes Mellitus dalam Dipiro, JT, Talbert RI, Yee, GC, Matzke GR, Wells BG, dan Posey LM, (Eds), Pharmacotherapy : $A$ Pathopysiologic Approach, $6^{\text {th }}$ Ed., Appletton\& Lange, New York, pp.1333-1364

WHO., 2009, Integrated Chronic Disease Prevention and Control. www.who.int

Zimmet, P., 2009., Preventing Diabetic Complication: A primary care prospective, diabetes ras clin pract 84:107-116. 